\title{
Uma formação intelectual e social convenientes [...]: formação de professores rurais (Brasil, 1942-1963) ${ }^{1}$
}

Una formación intelectual y social convenientes [...]: formación de profesores rurales (Brasil, $1942-1963)$

Suitable intellectual and social training [...]: rural teacher training (Brazil, 1942-1963)

\author{
Nilce Vieira Campos Ferreira \\ Universidade Federal de Mato Grosso (Brasil) \\ http://lattes.cnpq.br/3948893613479712 \\ http://orcid.org/0000-0002-9165-0011 \\ nilcevieiraufmt@gmail.com \\ Sandra Cristina Fagundes de Lima \\ Universidade Federal de Uberlândia (Brasil) \\ http://lattes.cnpq.br/7347582428774239 \\ https://orcid.org/0000-0001-7191-7914 \\ sandralimaufu@gmail.com
}

\section{Resumo}

No período de 1942 a 1963, com incentivo e apoio do governo federal brasileiro, houve significativa expansão de cursos de formação de professores rurais. Tais cursos deveriam ser ministrados nas Escolas Rurais ou Escolas Regionais Brasileiras. O objetivo deste artigo é compreender se, organizados sob a égide de uma formação específica para o magistério rural, esses cursos, no período em questão, organizaram a formação das normalistas em consonância com a realidade na qual se inseria a população rural. Os questionamentos que nos motivam são: como foram propostos os cursos normais rurais no Brasil e quais eram os modelos educativos para a formação de professores rurais? O que definia um curso normal rural, o meio no qual ele se localizava ou os conteúdos ministrados? Compõem fontes desse estudo: anais da VIII Conferência Nacional da Educação (Goiânia, 1942) e artigos publicados nas revistas da Campanha Nacional de Educação Rural (CNER) e na Revista Brasileira de Estudos Pedagógicos (RBEP). A análise da trajetória dos Cursos Normais Rurais na perspectiva da ação do Estado e da política educacional destinada à formação dos professores das escolas rurais permitiu concluir que, embora em tais cursos estivesse subjacente a proposta de uma formação específica para a atuação no meio rural e, portanto, uma concepção didáticopedagógica e uma organização administrativa diferentes daquelas vigentes nas escolas normais urbanas, na prática, nos Cursos Normais Rurais prevaleciam concepções formativas voltadas para a escola única.

Palavras-chave: História da Escolarização Rural. Formação de Professora(e)s Rurais. Curso Normal Rural. Curso Regional. Campanha Nacional de Educação Rural.

\footnotetext{
${ }^{1}$ Pesquisa desenvolvida no estágio de Pós-doutorado realizado no Programa de Pós-Graduação em Educação da Universidade Federal de Uberlândia, sob a supervisão da Prof ${ }^{a}$. Dr ${ }^{a}$. Sandra Cristina Fagundes de Lima. O texto também se inscreve no âmbito do projeto de pesquisa: Formação e Trabalho de Professoras e Professores Rurais no Brasil: PR, SP, MG, RJ, MS, MT, PE, PI, SE, PB, RO (décadas de 40 a 70 do século XX), coordenado por Rosa Fátima Souza Chaloba, Araraquara-SP, 2016.
} 


\begin{abstract}
From 1942 to 1963, there was significant expansion of training courses for rural teachers, with the encouragement and support of the Brazilian federal government. Such courses were to be given in rural schools or Brazilian regional schools. The aim of this article is to learn if, under the auspices of specific training for rural teachers, these courses were organized according to the reality of the rural population at that time. The following issues prompt this study: How were rural teacher training courses proposed in Brazil, and which educational models were followed for training of rural teachers? What defined a rural teacher training course, the environment it aimed to serve or the content taught? The sources of this study were the annals of the 8th Brazilian Education Congress (Goiânia, 1942) and articles published in the journal of the National Rural Education Campaign and the Brazilian Journal of Pedagogical Studies. The approach taken in the rural teacher training courses, within the perspective of specific government action and educational policy for this type of training, was analyzed. It revealed that, although a proposal of specific training activity for work in a rural environment, and thus a didacticpedagogical conception and administrative organization different from those in effect in the urban teacher training schools, , underlay such rural teacher training courses, in practice, educational conceptions directed toward a single-model school prevailed.
\end{abstract}

Keywords: History of rural schooling. Rural teacher training course. Regional course. National rural education campaign.

\title{
Resumen
}

En el periodo de 1942 a 1963, con incentivo y apoyo del gobierno federal brasilero, hubo una significativa expansión de cursos de formación de profesores rurales. Tales cursos deberían ser suministrados en las Escuelas Rurales o Escuelas Regionales Brasileras. El objetivo de este artículo es comprender si, organizados bajo la protección de una formación específica para el magisterio rural, estos cursos, en el periodo en cuestión, organizaron la formación de los normalistas en consonancia con la realidad en la cual se incluía a la población rural. Los cuestionamientos que nos motivan son: ¿cómo fueron propuestos los cursos normales rurales en el Brasil y cuáles eran los modelos educativos para la formación de profesores rurales? ¿Qué definía un curso normal rural, el medio en el cual se localizaba o los contenidos suministrados? Componen fuentes de ese estudio: anales de la VIII Conferencia Nacional de la Educación (Goiânia, 1942) y artículos publicados en las revistas de la Campaña Nacional de la Educación Rural (CNER) y en la Revista Brasilera de Estudios Pedagógicos (RBEP). El análisis de la trayectoria de los Cursos Normales Rurales en la perspectiva de la acción del estado y de la política educacional destinada a la formación de los profesores de las escuelas rurales permitió concluir que, aunque en tales cursos estuviese subyacente la propuesta de una formación específica para la actuación en el medio rural y por lo tanto, una concepción didáctico-pedagógica y una organización administrativa diferente de aquellas vigentes en las escuelas normales urbanas, en la práctica, en los Cursos Normales Rurales prevalecían concepciones formativas enfocadas para la escuela única.

Palabras-clave: Historia de la Escolarización Rural. Formación de Maestros en Entornos Rurales. Curso Normal Rural; Curso Regional. Campaña Nacional de la Educación Rural. 


\section{Introdução}

A formação de professoras/professores para atuar nas escolas rurais no período de 1942 a 1963 recebeu considerável incentivo do governo federal brasileiro. Segundo Manoel Bergström Lourenço Filho (1953), experiências pioneiras já ocorriam desde os anos de 1930, mas foi somente com a promulgação da Lei Orgânica do Ensino Normal, em janeiro de 1946, que esse movimento se expandiu. Com isso, no ano de 1951, funcionavam no Brasil 121 cursos regionais, assim chamados os cursos normais rurais que tinham uma estrutura mais flexível, de acordo com as regiões nas quais se instalaram.

Lourenço Filho (1953, p. 51) destacou que a maioria desses cursos regionais destinados à formação de professoras/professores rurais ainda não apresentava perfeitas condições de organização e funcionamento como os cursos normais rurais em funcionamento, mas que realizavam "trabalho digno de ser reconhecido e analisado".

A formação especializada para professores rurais foi defendida por Lourenço Filho (1953), ao relatar que, não obstante nosso país ser o primeiro da América a criar escolas normais mantidas pelo poder público, em um inquérito que realizara constatou que $48 \%$ dos mestres em serviço nas escolas primárias não tiveram oportunidade de receber qualquer preparação pedagógica. No texto Preparação de Pessoal Docente para Escolas Primárias Rurais, um estudo publicado na Revista Brasileira de Estudos Pedagógicos (RBEP), preparado por solicitação da UNESCO, Lourenço Filho (1953) enfatizou as diferenças do ensino no país. Elucidou que na região Sul, mais densamente povoada, economicamente ativa e em franca industrialização, a taxa de mestres que não passaram por escolas normais era de apenas 10\%; em São Paulo, na região Sudeste, os estabelecimentos de educação primária no período já não mais contavam com regentes leigos² .

Nas regiões brasileiras do Norte, Nordeste e Centro-Oeste, contudo, prevalecia a atuação no magistério de mestres improvisados, como também eram chamados os professores leigos ou ainda aqueles que não eram habilitados, chegando a compor um universo de 70 a $80 \%$ dos professores em atividade, não só atuando nas escolas primárias das zonas rurais, mas também nas escolas das pequenas cidades e vilas ${ }^{3}$. Nesse Brasil rural daqueles anos, os sujeitos " "[...] trabalhavam, constituíam as suas famílias, praticavam a religião, desenvolviam laços de solidariedade e entravam em contato com os rudimentos da leitura, do cálculo e da escrita." (LIMA, 2009, p. 153).

Entre os anos 1940 a 1950, a taxa de urbanização do país era $36,2 \%$ - esse perfil praticamente se manteve até os anos de 1960, atingindo apenas 44,67\%, consoante os anuários estatísticos do IBGE -; índice desigualmente distribuído nas diferentes regiões do Brasil. (IBGE, 1950). Essa discrepância na dispersão demográfica e o tipo dispersivo do povoamento impediam uma boa organização escolar com consequente rendimento pedagógico e social, o que exigia medidas oficiais para atenuar o problema da falta de escolas no meio rural e o elevado índice de analfabetismo que se mantinha nos estados brasileiros.

Lourenço Filho descreveu, em 1953, que a população rural se encontrava dispersa em casas isoladas ou núcleos com poucas habitações, muito distanciados uns dos outros, em especial nas regiões Centro-Oeste e Norte, com densidade demográfica de 1 habitante por $\mathrm{Km}^{2}$, que ocupavam duas terças partes do território brasileiro. As aglomerações com mais de 5.000 habitantes, em conjunto, conforme o recenseamento de 1940, não representavam um quinto da população, o que configurava "[...] extensas zonas do país não suscetíveis de receber

\footnotetext{
2 Tal denominação usualmente empregada para definir o professor leigo de carreira, em geral a pessoa que, sem nunca haver chegado à posição de um professor formado, dedicou quase toda a sua vida ao magistério, principalmente em áreas rurais. (BRANDÃO, 1986).

${ }^{3}$ Embora Lourenço Filho tenha destacado que São Paulo, estado situado na região Sudeste Brasileira, não contasse mais com professores leigos, a realidade em Minas Gerais, também situada na região Sudeste, era similar a das regiões Norte, Nordeste e Centro-Oeste.
} 
organização escolar de tipo nenhum”; representavam, portanto, “[...] espaços não escolarizáveis." (LOURENÇO FILHO, 1953, p. 63).

Mas a verdade é que a população assim não se distribui. A densidade demográfica é variável de região a região. Apresenta-se apenas como 1,08 habitante por km2 no Norte, isto é, nos Estados de Amazonas, Pará, Maranhão, Piauí e Território do Acre (população de 4.231.545, para uma área de 3.928.789 km2). É de 21,41 hab./km2 nos Estados do Nordeste: Ceará, Rio Grande do Norte, Paraíba, Pernambuco, Alagoas (população de 8.238.744, para $384.747 \mathrm{~km} 2$ ). Exprime-se com índice de 9,43 na Região Este, com Sergipe, Bahia e Espírito Santo (população de 5.619.613, para 595.615 km2). Alcança 18,56 nos Estados do Sul, com Rio de Janeiro, São Paulo, Paraná, Santa Catarina, Rio Grande do Sul (população de 16.167.806, para $870.994 \mathrm{~km} 2$ ). E finalmente de 3,29 nos estados do Centro: Mato Grosso, Goiás e Minas Gerais (população de 8.989.223, para 2.731.044 km2). Ainda dentro de cada região, a densidade é extremamente variável. Assim, no Norte, oscila entre 0,25 (Amazonas) e 3,25 (Maranhão). Na região do Nordeste, entre 11,43 (Ceará) e 43,30 (Alagoas). No Este, entre 8,18 (Bahia) e 26,07 (Sergipe). No Sul, entre 5,34 (Paraná) e 49,76 (Estado do Rio). No centro, entre 0,26 (Mato Grosso) e 13,19 (Minas Gerais). (LOURENÇO FILHO, 2002, p. 39).

Para Lourenço Filho, um plano de caráter nacional deveria considerar essas desigualdades entre as regiões brasileiras para determinar a área «escolarizável», de modo a criar e distribuir escolas para obter o rendimento desejado e romper com os altos índices de analfabetismo do país.

O período que remonta aos anos de 1942 e se estende até os anos de 1963, portanto, reveste-se de significados para a história da educação rural brasileira. De fato, em 1942, na VIII Conferência Nacional da Educação, denominada VIII Congresso Nacional de Educação realizada em Goiânia-Go nos dias 18 a 28 de junho de 1942 -, a temática foi o ensino rural. A partir de 1950 efetivaram-se medidas institucionais com o objetivo de solucionar o problema da escolaridade nas regiões rurais. Entre essas medidas, foi iniciada a campanha empreendida pela CNER em 1953 e que seria extinta em 1963.

Ao longo dos anos em que a CNER atuou foram publicadas nove Revistas, nas quais foi possível identificar informações sobre os cursos normais rurais, tais como: Centros de Treinamento de Professores Rurais, cursos e habilitações de professores rurais ofertados, práticas propostas pelo Ministério de Educação e Cultura, ações propostas pelo Serviço Social Rural, estruturação de Centros Regionais de Treinamento de Professores Rurais, missões rurais e escola primária, entre outros.

Partindo, portanto, dessas evidências buscamos analisar como foram propostos os cursos normais rurais no Brasil e como se dava o funcionamento desses cursos no período de 1942 a 1963. Nosso propósito foi compreender se era adotado um modelo escolar diferenciado, ou seja, se eram adotadas práticas pedagógicas distintas daquelas prescritas pela legislação e aplicadas nas escolas urbanas. Para tanto, examinamos normas e concepções que regulamentavam o funcionamento das escolas normais rurais no Brasil e as propostas que foram erigidas por aqueles que geriam esse tipo de formação.

Procuramos, assim, compreender se, organizadas sob a égide de uma formação para o magistério rural, existiam, de fato, prescrições de práticas específicas estabelecidas para essa formação que pudessem ser desenvolvidas pelas normalistas em consonância com os anseios da população rural. Nessa linha de raciocínio, os questionamentos que nos motivam são: como 
foram propostos os cursos normais rurais no Brasil e quais eram os modelos educativos para a formação de professores rurais? O que definia um curso normal rural, o meio no qual ele se localizava ou os conteúdos ministrados?

A nossa hipótese é que, embora houvesse no âmbito dos cursos normais rurais a proposta de uma formação específica para a atuação no meio rural, permanecia uma formação voltada para a escola única. Às práticas docentes dos professores das escolas rurais subjaziam as práticas da escola urbana, o que denuncia a falta de identidade desses cursos. Assim, partimos do aparente aparelhamento dos cursos normais rurais para, então, cotejarmos essa organização escolar com as propostas constituídas no âmbito da CNER.

\section{Não seria importante "O tamanho ou o currículo da Escola Normal. O que importa é que crie mentalidade".}

No que concerne aos rumos da educação rural no Brasil, como já apresentado, conhecimentos rudimentares de leitura, cálculo e escrita chegavam de maneira informal aos rurícolas em seu próprio ambiente doméstico e lhes serviam para a lida diária com o trabalho agrícola. Em escolas distantes do meio urbano, contudo, predominava uma relutância dos professores normalistas em atuarem no meio rural, já que suas escolas não gozavam de prestígio, muito embora o meio rural na época abrigasse a maior parte da população brasileira.

Sud Mennucci já alertava desde 1930 que os próprios docentes promoviam uma campanha negativa de tais instituições, pois se sentiam mal nas escolas rurais, delas querendo sair, e esclarecia que "enquanto espera que o retirem do degredo e do suplício, promove a campanha negativista e perniciosa que combate o amor pela vida campesina." (SUD MENUCCI, 1934, p. 73). Para esse autor, leis caracteristicamente urbanistas incentivavam a permanência de professoras/professores na cidade e dificultavam o ingresso ou permanecia nas localidades rurais.

A respeito das políticas educacionais voltadas para educação rural, Sud Menucci (1934, p. 132) já destacara as precárias condições das escolas rurais, nas quais o processo escolar, a priori, continuava inalterado após a instalação da República. Para esse autor, outro fenômeno também contribuía para isso, a saber, "os professores que vão para o campo são os que menores vencimentos têm. A regra é perceberem um terço menos, advindo desse fato que a zona rural é que recebe os neófitos, isto é, os noviços mal saídos das escolas normais."

Podemos perceber que, salvo raríssimas exceções, como o exemplo da Escola de Juazeiro do Norte (BARROS, 2011) e, posteriormente, na Fazenda do Rosário (PINHO, 2009), a oferta de cursos para professoras/professores rurais, bem como a organização da educação destinada à população rural não vinha sendo encarada de perto pela administração do país, ou, se o era, isso se vinha fazendo sem nenhuma continuidade, haja vista a ausência de uma continuidade de políticas que estabelecessem o ensino rural como prioridade nos estados, nos municípios ou na União.

No ano de 1942, essa realidade da educação rural sobressaiu-se durante o VIII Congresso Brasileiro de Educação, no qual foram discutidos problemas básicos, tais como o elevado número de analfabetos que residia nas áreas rurais e os movimentos migratórios do homem rural para as cidades. Naquele Congresso, embora prevalecesse um discurso conservador e nacionalista, não se definiram claramente os rumos da educação rural brasileira, tornando-se consenso, contudo, que era necessário envidar esforços em prol do ensino rural, com vistas ao desenvolvimento social e cultural que o próprio Estado reclamava. (LEITE, 1999).

Sud Mennucci, em seu relatório denominado "O professor primário das zonas rurais: formação, aperfeiçoamento, remuneração e assistências”, defendeu que era preciso um novo professor formado em uma escola normal especializada que ofertasse sólida formação com amplos conhecimentos de agricultura, de indústrias rurais, de economia rural e que entendesse de profilaxia, higiene e dietética. Além disso, o professor deveria atuar como um líder na comunidade. (SUD MENUCCI, 1944). 
De acordo com Sud Menucci, a escola urbana nunca conseguiria formar «professores desse tipo». Como exemplo de resultado também citou o estabelecimento criado para o preparo do mestre rural: a Escola Normal Rural de Juazeiro, que desde 1937, segundo ele, já formava professores rurais com excelentes resultados. Contudo, embora defendesse a criação das escolas normais rurais no mesmo molde da Escola de Juazeiro, aceitou como viável outro tipo de escola para cada estado, desde que fosse uma escola normal rural e que desse ao mestre formado a especialização agrícola "de técnico destinado ao campo, para suas fainas e labutas", pois não seria importante "[...] o tamanho ou o currículo da escola normal. O que importa é que crie mentalidade." (SUD MENUCCI, 1944, p. 291).

Em uma síntese das discussões apresentadas e relacionadas à formação da professora/professor rural, Mennuci apresentou as seguintes conclusões à plenária no VIII Congresso Brasileiro de Educação:

I. É imprescindível a formação de cunho especializado para o professor rural, fato esse já assente e estabelecido pela Comissão Nacional de Ensino Primário.

II. Essa formação tem que ser obtida por meio de instituto que cuide de preparar o mestre, dando-lhe conhecimento das técnicas agrícolas e práticas sanitárias afim de que ele possa assistir e liderar a comunidade em que trabalha.

III. Esses institutos devem ser escolas normais rurais, com um currículo que o estado determinará e que aconselhamos seja o atualmente adotado pela escola de Juazeiro, do Ceará, capaz de servir a todas as circunscrições da República.

IV. O professor rural, em virtude das dificuldades com que luta e da perda de conforto a que se submete, deve ganhar mais que o professor urbano. Em qualquer hipótese nunca deverá ganhar menos, ponto de vista esse já vitorioso na legislação de São Paulo.

V. A assistência ao professor rural deve abranger múltiplos aspectos: a) técnica - pelas frequentes visitas de autoridades orientadoras, tanto pedagógica, como sanitárias e agrícolas; b) intelectual - pelo fortalecimento gratuito de periódicos e revistas e pelo empréstimo de livros de bibliotecas circulantes; c) social - pela organização da defesa da saúde do professor e sua família, organizando o estado, pelo sistema cooperativo, um serviço odontológico, farmacêutico e médico; pelo fornecimento daqueles melhoramentos que são o conforto das cidades: rádio, telefone, luz elétrica, cinema; d) moral - pelas preferências que o estado outorgará ao mestre do campo, no sentido de que esse possa educar a prole, encaminhando-a à vida prática.

VI. O aperfeiçoamento do professor rural deve, de preferência, fazerse pelos cursos intensivos em institutos que cuidem das atividades que interessem à escola rural, pelos cursos de férias e pelas visitas e excursões de caráter educativo. (SUD MENUCCI, 1944, p. 300).

$\mathrm{Na}$ defesa da escola normal rural e pelo aperfeiçoamento, formação e melhores condições de trabalho para o professor rural, Sud Mennucci apelou para que Getúlio Vargas, então Presidente da República, fundasse e mandasse instalar uma Escola Normal Rural em cada circunscrição política da Nação, para atender as peculiaridades regionais. 


\section{"Nem todos os programas servem para todas as crianças [...]"}

Muito do que fora descrito por Mennucci em 1942, no VIII Congresso Nacional de Educação, marcaria a Lei Orgânica do ensino Normal de 1946 e, de modo mais significativo, a campanha empreendida pela CNER. Naquele congresso fora consenso que a professora/o professor destinado às escolas rurais deveria ter a sua formação profissional no meio rural, ou quando não fosse possível, ali deveriam ser criadas escolas complementares ou cursos de especialização que seriam oferecidos em períodos específicos e de forma diferenciada para que uma vez docentes ali formadas/formados pudessem adquirir a mentalidade, os hábitos, costumes e tarefas daqueles que vivam no campo. Afinal, o urbanismo causava «males sem conta» ao bem-estar social e cabia à escola normal rural tornar-se um centro com acentuada influência civilizadora sobre a comunidade no seu entorno, por extensão, contendo o fluxo migratório do meio rural para as cidades.

Observamos nos discursos dos conferencistas do VIII Congresso Nacional de Educação que era preciso, por meio da escola, contando com o auxílio da professora/do professor, ao mesmo tempo motivar a permanência das comunidades no campo e promover o desenvolvimento moral, econômico e social das localidades com a incorporação dos cuidados com a saúde e da higiene no projeto político de formação nas escolas normais rurais.

Ao descrever a situação do Estado de Mato Grosso no aludido Congresso, Gervásio Leite esclareceu que seria inútil sobrecarregar as escolas com um programa de letras extenso e que não estivesse em harmonia com as necessidades regionais. Para ele, a organização da escola rural "precisa ser diferente da escola urbana. E diferentes precisam ser também o professor, o programa, o método, o prédio." O congressista mato-grossense defendeu intensa campanha "de fixação do homem ao solo", isso porque, em suas palavras, do "contrário, continuaremos sendo vítimas desse urbanismo que nos infelicita." (LEITE, 1944, p. 136).

Para isso, ainda segundo Leite, não bastava promover a organização das escolas, mas era "indispensável o estabelecimento adequado capaz de formar professores rurais, inclinados à vida rural." Desse modo, a escola normal rural deveria facilitar aos professores "conhecimento de noções e práticas modernas de agricultura, de higiene, e de saneamento", o que por sua vez evitaria um "ensino urbanizado que faça da cidade um permanente centro de atrações." (LEITE, 1944, p. 139).

Gervásio Leite ainda complementou que enquanto professoras/professores não possuíssem "suficiente preparo todas as reformas serão inúteis, os programas desnecessários e os métodos ornamentos." Para esse autor, a solução desse problema seria a criação de cursos especializados para preparar o professor rural. E acrescentou: "nem todos os programas servem para todas as crianças, nem os livros, nem os métodos, o que claramente evidenciava a distinção que deveria ser dada à formação na escola rural.” (LEITE, 1944, p. 139-140).

A defesa da escola normal rural diferenciada da urbana com uma formação de professoras/professores com consciência agrícola e sanitária foi intensamente debatida no VIII Congresso Nacional de Educação, prevalecendo a concepção de uma escola de formação que desse à/ao docente gosto pelos labores da vida rural. Aliado a isso, a escola normal rural deveria abranger uma formação de elevado espírito social, de civismo, a compreensão da função moral do magistério e das possibilidades da escola como fator de elaboração cultural e econômica, funcionando como mais uma possibilidade de contenção ao fluxo migratório, com acentuada influência civilizadora das comunidades nas quais a professor/professor atuaria. Conforme advertiu um dos conferencistas:

Males sem conta tem causado a nossa economia e ao nosso bem-estar social a praga do urbanismo. Professores para o campo e professores para a cidade, é que deve ser a norma, dando-se margem só a que mudem os mesmos de ambiente, porém com conveniente e obrigatória 
adaptação funcional [...] a escola normal rural, tendo matérias específicas, será diversa da escola normal urbana, tanto no desenvolvimento de seus programas, como nas suas práticas e no espírito que a deve animar. (SOUSA, 1944, p. 303).

As diretivas fixadas pelos congressistas continham aspectos múltiplos que articulavam uma ampla preocupação com o aprimoramento geral do ensino rural. Algumas recomendações que resultaram do VIII Congresso foram: a organização da educação primária fundamental nas zonas rurais; provimento de escolas para toda população com adequados prédios para escolas primárias e padrões de aparelhamento escolar, consideradas as peculiaridades regionais; formação, aperfeiçoamento, remuneração e assistência adequada para o professor primário das zonas rurais; destinação de recursos em matéria de educação popular; criação de colônias escolas como recurso para colonização de áreas rarefeitas; estabelecimento de internato e semiinternatos para estimular a frequência regular às escolas e implementação de missões culturais como instrumento de penetração cultural.

\section{"Por mais de uma vez nos temos rebelado contra essa escola que faz o mestre de olhos voltados para a cidade, inteiramente esquecido do campo".}

Como vimos, a preocupação com a formação de professoras/professores para a atuação nas escolas rurais foi o mote do VIII Congresso Nacional de Educação. A criação de escolas normais rurais foi defendida como socialmente necessária por oferecer aos rurícolas uma educação sadia e estimulante para a vida em suas localidades, ficando subentendido que as escolas normais brasileiras existentes não estariam preparadas para fazê-lo. Esse aspecto pode ser inferido pelo reforço que os documentos analisados davam à educação no sentido de que a escola rural deveria ser organizada como uma "empresa da sociedade", na qual por meio do ensino e do aprendizado das disciplinas escolares, professoras/professores empregariam técnicas auxiliares e métodos educativos de vida e de trabalho da comunidade que deveriam se refletir nas atividades cotidianas dos alunos, priorizando as ocupações dominantes da região.

A escola rural deveria, ainda, constituir-se em um espaço de iniciação econômica e profissional, com o objetivo de assegurar o conhecimento elementar de um oficio, de racionalizar o trabalho dos pais, além de tornar-se um centro de convergência dos interesses locais, estendendo a influência civilizadora à comunidade local, contribuindo para a elevação do nível de instrução do povo, para o aumento do conforto geral e para o desenvolvimento da economia regional.

Não basta, porém, que a escola normal rural, para a formação de um professorado capaz de dar consciência agrícola e sanitária às populações rurais, além da exata compreensão do valor da providência e da economia, se situe em centro agrícola, é necessário, sobretudo, que esteja animada de um espírito tal que contribua, pelo preparo conveniente do professor, para que a escola primária rural se torne um centro de iniciação de econômica e profissional com acentuada influência civilizadora sobre toda a comunidade do lugar onde estiver. (SOUSA, 1944, p. 303).

Para isso, órgãos governamentais e a escola deveriam promover conferências públicas, festividades patrióticas e associações para fins culturais, cívicos e recreativos, afinal, se os serviços de assistência e educação estivessem próximos aos rurícolas, mais facilmente seria possível estimular a permanência em suas localidades e convencê-los de que as autoridades educacionais estabeleciam como prioridade a organização de um sistema público de ensino adequado para criar as bases sociais para a modernização de sua região. 
Às professoras/aos professores cabiam, portanto, ensinar e, ao mesmo tempo, compor uma feição antiurbanista, o que implicava que não deveriam apenas ser higienistas, mas também portadoras e portadores de uma visão lúcida e lógica dos problemas do campo, empreendendo uma cruzada contra a ignorância e o abandono das zonas rurais, modificando a escola e, com isso, evitando o desenraizamento da população nos campos. Nessa defesa por criação de escolas normais rurais brasileiras, Sousa destacou que "por mais de uma vez nos temos rebelado contra essa escola que faz o mestre de olhos voltados para a cidade, inteiramente esquecido do campo." (SOUSA, 1944, p. 302). Para ele, o "espírito governamental" deveria prover às populações campesinas escolas diversas das urbanas e que se tornassem "centros de iniciação econômica".

Na exposição de motivos n. 155, de 31 de dezembro de 1945, relativa à Lei Orgânica do Ensino Normal, Raul Leitão da Cunha, Ministro da Educação e Saúde, expôs que dois níveis eram necessários para a formação de pessoal docente para atuar no grau primário, dadas as diferenças de ordem econômica e cultural que existiam entre as várias regiões do país. $\mathrm{O}$ primeiro nível de estudo corresponderia ao ciclo inicial dos cursos de segundo grau, composto por quatro anos de estudos, com a finalidade de habilitar regentes para o ensino primário. $\mathrm{O}$ segundo nível corresponderia ao segundo ciclo desse mesmo grau de ensino, mas seria efetivado em três anos, após a conclusão do primeiro nível, e formaria professores primários habilitados para o magistério primário, permitindo também que o ciclo de estudos pudesse ser concluído em dois anos de estudos intensivos nas escolas regionais.

Para o Ministro da Educação e Saúde, Raul Leitão da Cunha, o Decreto Lei n. ${ }^{\circ}$ 8.529, de 02 de janeiro de 1946, deveria adotar essa estrutura, pois tal diferenciação seria necessária à preparação de professores para atuar no magistério primário, uma vez que alguns educadores propunham as escolas normais rurais. Para ele, o Decreto-Lei n. ${ }^{\circ} 8.530$, de 2 de janeiro de 1946, deveria ampliar a ideia de escolas normais rurais, admitindo o estabelecimento de cursos normais regionais, com estrutura flexível, de acordo com as localidades nas quais estariam inseridas, podendo ser tanto de sentido nitidamente agrícola, como de economia extrativa, ou ainda de atividades peculiares às zonas do litoral, coadunando com os «meios adequados à consecução da educação democrática», como havia sido definido em junho de 1945 no IX Congresso Brasileiro de Educação, realizado pela Associação Brasileira de Educação.

Meios Adequados à Consecução da Educação Democrática: a) flexibilidade dos cursos e ramos; b) acessibilidade das escolas públicas a todos, pelo número das mesmas, pela gratuidade do ensino de todos os graus e ramos e pela assistência aos educandos necessitados; c) obrigatoriedade de um mínimo de cultura geral comum para todos; d) medidas que favoreçam o ensino de acordo com as diferenças ocasionais; e) liberdade de cátedra; f) liberdade de ensino com as garantias de sua moralidade e eficiência; g) unidade de diretrizes fixadas por uma política nacional de educação, e diversidade estrutural de sistemas educacionais em conformidade com as condições especiais de cada região do país; h) atividades escolares que desenvolvam o espírito de iniciativa pessoal e o hábito de cooperação; i) introdução nas escolas de todos os graus e ramos do ensino dos princípios e do mecanismo do regime democrático, ensino que deve ser acompanhado na vida escolar da prática sistemática e exemplos de instituições democráticas; j) serviço de orientação educacional. (RBEP, 1945, p. 260).

Para os estudos do segundo ciclo deveria ser adotado um curso com duração de três anos, como os já existentes em várias localidades brasileiras, composto por um currículo mínimo e conveniente seriação de disciplinas. Era permitida a oferta do mesmo curso em dois 
anos de estudos intensivos nas escolas regionais, consideradas mais adequadas à realidade das diversas regiões do país, pois seria necessário maior enriquecimento dos estudos, onde isso fosse possível. As normas de organização do ensino deveriam obedecer a um princípio de flexibilidade a fim de que, sem quebra da coordenação nacional necessária, pudesse encontrar «O ensino normal nos seus vários tipos estaduais todas as possibilidades de constante aperfeiçoamento". (RBEP, 1945, p. 261).

\section{"Larga campanha de educação para as gentes do campo devem constituir os instrumentos mais adequados ao levantamento do nível de vida material e cultural das populações brasileiras."}

Em 1949, no Seminário Interamericano de Educação de Adultos, realizado em Petrópolis, patrocinado pelo Governo Brasileiro, pela UNESCO e pela União Panamericana, José Irineu Cabral, Diretor do serviço de Informação Agrícola, e Manuel Bergström Lourenço Filho, naquele momento Diretor do Departamento Nacional de Educação, alinhados aos entendimentos defendidos pelos congressistas no VIII Congresso Nacional de Educação, realizado em 1942, propuseram um ensino de educação de base visando à recuperação e desenvolvimento de comunidades rurais.

A partir daí, em 1950, em Itaperuna, no Rio de Janeiro, foi fundada a $1^{\text {a }}$ Missão Rural com a intenção de obter o maior número de elementos que permitissem indicar diretrizes técnicas de processos educativos e assistenciais que pudessem promover a melhoria de condições de vida econômica e social do meio rural. Na Escola de Itaperuna, o método utilizado seria fundamentado na organização social da comunidade e o instrumento de execução seria uma missão rural para a educação de adultos.

Coerente com a concepção do governo brasileiro de que as escolas rurais serviram para evitar o fluxo migratório rural-urbano, Robert King Hall, professor do Teachers College, Universidade de Columbia, veio ao Brasil financiado pelo governo americano, para ser colaborador do INEP, na criação do modelo para as escolas rurais que iriam ser instaladas no país. Robert King Hall no relatório que apresentou ao Instituto Nacional de Estudos Pedagógicos (INEP), quando encerrou suas atividades como professor do Seminário de Educação Rural, inseriu observações e impressões sobre o plano para formações de professores rurais que estava em curso na Escola Normal Rural de Juazeiro na região Norte brasileira, na Escola de Itaperuna no Rio de Janeiro e na escola de formação de professores rurais idealizada por Helena Antipoff para Curso Normal Rural da Fazenda do Rosário em Minas Gerais, e que, segundo ele, ajudava "a radicar o professor rural na zona rural e tende a diminuir os desajustamentos do professorado, com o consequente êxodo para as cidades." (HALL, 1950, p. 114). Hall, textualmente, ressaltou que a criação dessas escolas poderia estimular a permanência da população no campo, bem como conter o fluxo migratório para as cidades.

Para isso o plano serve-se de três meios. Primeiro, seleciona os professores dentro da própria localidade, escolhendo pessoas que tenham laços de família no lugar, que compreendam o ambiente da comunidade e nele estão integradas, pessoas que não sentirão a frustração e o descontentamento de um professor urbano, transplantado para o campo e aí isolado. Segundo, prove, com a escola normal rural, um meio de educar o professor rural na própria zona rural, evitando assim o grande perigo de que o professor, após o processo de formação profissional, na capital do 
Estado ou em qualquer outra grande cidade, fique tão sofisticado e «urbanizado» que não deseje regressar à zona rural. E terceiro, prove, com a residência anexa à escola primária rural e parte integrante da mesma, um poderoso incentivo para que o professor se fixe na comunidade e sinta orgulho de sua profissão. Quase sem exceção, as residências dos professores são as melhores residências do lugar. (HALL, 1950, p. 114).

Essas propostas para a educação brasileira dos anos de 1950 surgiram, portanto, em meio às discussões sobre a migração rural-urbana, considerada indesejada pela crescente ameaça à estabilidade nacional. As missões rurais comporiam um dos eixos do principal programa de formação de professores rurais: a Campanha Nacional de Educação Rural (CNER), com o objetivo explícito de conter essa migração rural-urbana e de estabelecer uma educação especificamente voltada para o meio rural. (CALAZANS; SILVA; CASTRO, 1985, p. 43).

Com o retorno de Getúlio Vargas à presidência da República, em 1950, o presidente autorizou o início do programa de base que viria a ser a CNER, sob a orientação dos organismos internacionais capitaneados pela Unesco.

Larga campanha de educação para as gentes do campo devem constituir os instrumentos mais adequados ao levantamento do nível de vida material e cultural das populações brasileiras [...] Não sendo possível conseguir novos processos de trabalho e melhores condições de vida sem um programa educativo de base, abrangendo o lavrador com sua família e as próprias instituições sociais de sua comunidade, devem, nesse sentido os Ministérios de Educação e da Agricultura articular seus esforços, planos e recursos financeiros e humanos. (VARGAS, 1951, p. 102-103).

Pouco depois, o Ministério da Educação e Saúde, cujo Ministro da Educação era Ernesto Simões Filho, oficializou a CNER, atribuindo-lhe a finalidade principal de "levar a educação de base ao meio rural brasileiro." (BRASIL, 1953). A CNER deveria alicerçar o seu trabalho na comunidade por meio da escola, fazendo dela a "cabeça de ponte para a grande investida contra a ignorância, a doença, o conformismo e, enfim, todo o atraso e abandono que conhecemos nas zonas rurais.” (ARREGUY, 1959, p. 84).

Embora o regulamento da CNER estabelecesse a nomenclatura «educação de base», como nas palavras de Getúlio Vargas, acabou por ser propagada no Brasil a denominação Educação Rural por ser mais compreensiva para o homem do interior e por "encontrar por toda parte um ambiente de simpatia e compreensão." (ROMERO, 1954, p. 185).

No âmbito da CNER, muito do que fora apresentado por Sud Mennucci no VIII Congresso Nacional de Educação, em 1942, antes da promulgação da Lei Orgânica do Ensino Normal de 1946, foi aproveitado. A CNER recomendava, a exemplo, que as professoras que atuavam no meio rural não deveriam ser formadas nas cidades para impedir sua migração para as cidades.

Parece-nos inteiramente desaconselhável a prática de trazer essas professoras do interior para treinamento na capital do país por maiores que sejam as facilidades de equipamentos oferecidas por esta. Num país como o nosso, a braços com o drama do êxodo rural, trazer professoras 
do interior para as grandes cidades é favorecer a migração para os centros urbanos. (ROMERO, 1954, 186).

A formação de professoras/professores na campanha empreendida pela CNER para atuação nas zonas rurais abraçava um imperativo: os cursos normais regionais deveriam seguir as diretrizes da Lei Orgânica do Ensino Normal (1946), mas em nível internacional deveriam atender à Recomendação n. 08 da UNESCO, de 13 de julho de 1936, proferida na Conferência Internacional da Educação Pública de Genebra, denominada A Organização da Educação Rural (UNESCO, 1979). A organização, as disciplinas e, sobretudo as práticas ensinadas, deveriam, portanto, inserir-se nas políticas internacionais.

O modelo das missões rurais que Lourenço Filho trouxera do México inspirava atividades educativas no ensino rural e propunha reformas no âmbito das políticas educacionais, estabelecendo medidas de desenvolvimento da educação rural e melhorias das instalações escolares rurais para que as famílias permanecessem no campo.

o complexo problema da educação rural era de natureza muito mais complexa. Não se poderia admitir a fórmula simplista de que a escola elementar pudesse «fixar o homem no campo», desde que ensinasse, ou se pretendesse ensinar às crianças, rudimentares técnicas agrícolas e de defesa da saúde. Muito embora toda e qualquer escola primária deva ter em conta o ambiente em que trabalhe, e seja desejável e necessária a preparação dos mestres nesse sentido, não se deverá pretender fazer nela nenhum ensino de caráter profissional. Para boa solução, o problema deveria exigir medidas de muito maior envergadura: reforma do regime agrário; desenvolvimento não só dos serviços de fomento da produção agrícola como de distribuição de crédito e defesa da produção; melhoria das vias de comunicação e serviços de assistência; serviços de educação de adolescentes e adultos analfabetos; «missões rurais» com o emprego de processos técnicos modernos de difusão, como os do cinema; e, enfim, melhoria das instalações escolares, construção de casas de residência para os professores, organização regional de sua formação, com atenção às necessidades gerais de vida em cada ambiente. (LOURENÇO FILHO, 2001, p. 11).

Segundo Lourenço Filho, as escolas existentes no meio rural se apresentavam, tanto se considerarmos a história de seu funcionamento quanto a dos recursos a elas destinados, caracterizadas pelos insuficientes investimentos do poder público em equipar e dotar essas instituições de ensino de condições favoráveis ao atendimento da população, cabendo, por conseguinte, um novo formato para a educação rural, o que justificava por sua vez, a implantação de uma campanha como a CNER.

No ano de 1951, consoante Lourenco Filho, funcionavam no Brasil 112 cursos normais regionais, distribuídos por estados, territórios e Distrito Federal, como se vê no Quadro 1. 
Quadro 1: Distribuição das Escolas Normais Rurais (Regionais)

\begin{tabular}{|l|c|c|}
\hline \multicolumn{1}{|c|}{ Estados } & $\begin{array}{c}\text { Cursos Normais Rurais } \\
\text { (Regionais) }\end{array}$ & Escolas Normais \\
\hline Alagoas & 2 & 6 \\
\hline Amazonas & 6 & 10 \\
\hline Bahia & 2 & 14 \\
\hline Ceará & 12 & 24 \\
\hline Espírito Santo & 1 & 14 \\
\hline Goiás & 6 & 22 \\
\hline Maranhão & 1 & 2 \\
\hline Mato Grosso & - & 3 \\
\hline Minas Gerais & 9 & 133 \\
\hline Pará & 2 & 6 \\
\hline Paraíba & 8 & 16 \\
\hline Paraná & 8 & 24 \\
\hline Pernambuco & 9 & 20 \\
\hline Piaú́ & 1 & 5 \\
\hline Rio Grande do Norte & - & 2 \\
\hline Rio Grande do Sul & 2 & 29 \\
\hline Rio de Janeiro & - & 20 \\
\hline Santa Catarina & 38 & 50 \\
\hline São Paulo & - & 135 \\
\hline Sergipe & 2 & 4 \\
\hline Território do Acre & 2 & 4 \\
\hline Território do Amapá & 1 & 1 \\
\hline Território do Guaporé & 1 & 2 \\
\hline Território do Rio Branco & 1 & 11 \\
\hline Distrito Federal & - & 434 \\
\hline Total & 12 & \\
\hline
\end{tabular}

Fonte: Lourenço Filho, 1953, p. 72.

Interessante notar que prevalecia uma contradição entre a importância desempenhada pela escola normal rural, quando a maioria da população habitava o campo e parte dela aí se escolarizava, como já apresentado, mas a formação da professora/do professor ocorria no meio urbano. Nessa concretude, a formação de professores não era realizada de modo a atender às necessidades do aluno habitante e trabalhador do meio rural. A CNER apoiava-se nesses dados e reforçava que a educação deveria ser consolidada pelos órgãos de educação formal, pois era "profundamente desoladora a situação em que se encontra o meio rural brasileiro no tocante à instrução. Não há instituições educativas, além das modestas e rudimentares escolas primárias e de alguns cursos de alfabetização de adultos." (SOUZA, 1956, p. 88).

Ou seja, de certa forma, o currículo, os horários, o calendário de avaliações e demais instrumentos que caracterizavam o seu funcionamento seguiam, no Brasil, as mesmas diretrizes vigentes nos estabelecimentos de ensino instalados no meio urbano (LIMA, 2009), nas quais a escola normal era o modelo da instrução básica no Brasil, contudo, para aqueles que estavam à frente da CNER, normalistas formadas/formados nas escolas urbanas, eram prejudiciais para a população campesina. 
Os professores egressos dessas Escolas prejudicam grandemente o ensino rural quando para este se dirigem. As Escolas Normais Rurais e Normais Regionais que devem preparar o professorado da zona rural, são em número muito mais reduzido, sendo que em alguns estados, as primeiras ainda nem foram criadas. (LOURENÇO FILHO, 1956, p. 97).

Podemos pensar, assim, que a preparação de professores para atuação no meio rural foi definida nas escolas normais rurais como um processo que deveria contribuir para modernizar o campo e civilizar o homem rural. Para isso, a CNER mobilizou elementos integrativos políticos, sociais e culturais para a formação oferecida nos cursos normais rurais e se utilizou dos recursos das missões culturais; assim, o homem do campo poderia ser integrado ao meio no qual vivia, estimulado pelas ações solidárias, cooperativistas e pela divisão do trabalho. A CNER, contudo, ao longo de seus anos de campanha, acabou por focar sua atuação nas missões rurais e na formação de professoras/professores normais, basicamente apoiando com bolsas a formação nas escolas de Itaperuna, do Rosário e de Juazeiro do Norte.

Em 1959, a CNER havia se voltado quase que tão somente para o desenvolvimento de técnicas educativas para a dinamização de grupos organizados por interesses que envolviam a organização de comunidades e a Educação de Base, norteando os rurícolas para o desenvolvimento do meio em que viviam com a participação das próprias comunidades e motivações realizadas pelas missões rurais que congregavam inúmeros cursos de extensão rural.

Quadro 2: Missões em 1959

\begin{tabular}{|l|l|}
\hline \multicolumn{1}{|c|}{ Nome da Missão Rural } & \multicolumn{1}{c|}{ Estado } \\
\hline Missão Rural de Campo Maior & Piauí \\
\hline Missão Rural de Vale do Mearim & Maranhão \\
\hline Missão Rural de Vale do Apodi & Rio Grande do Norte \\
\hline Missão Rural de Vale do Açu & Rio Grande do Norte \\
\hline Missão Rural de Caraúbas & Rio Grande do Norte \\
\hline Missão Rural da Região do Agreste & Rio Grande do Norte \\
\hline Missão Rural de Vale do São Francisco & Pernambuco \\
\hline Missão Rural de Palmeira dos Índios - Arapiraca - Santana do Ipanema & Alagoas \\
\hline Missão Rural de Feira de Santana & Bahia \\
\hline Missão Rural Auxiliar da Feira de Santana & Bahia \\
\hline Missão Rural da Região do Recôncavo & Bahia \\
\hline Missão Rural Auxiliar da Região do Recôncavo & Bahia \\
\hline Missão Rural do Baixo Itapicuru & Bahia \\
\hline Missão Rural de Bonfim & Bahia \\
\hline Missão Rural de Caratinga & Minas Gerais \\
\hline Missão Rural de Taquara & Rio Grande do Sul \\
\hline Missão Rural de Sapiranga & Rio Grande do Sul \\
\hline Missão Rural de Santo Antônio da Patrulha & Rio Grande do Sul \\
\hline
\end{tabular}

Fonte: Arreguy, 1959, p. 280.

No mais, a CNER mantinha os Centros Regionais de Educação de Base (CREB) em: Itapagé, no estado do Ceará; Ponta Negra, no estado do Rio Grande do Norte; Apiaí, no estado de São Paulo; Colatina, no Espírito Santo. Tais centros eram destinados a oferta de cursos e de treinamento para professoras/professores rurais; cursos de treinamento para educadores de base em caráter regional e curso de habilitação para professoras rurais. Voltados para a juventude feminina, tinham a finalidade de transformar "os hábitos das famílias e das comunidades rurais, despertando-lhes o sentido comunitário para o conhecimento e solução individual e comum de 
seus problemas." (ARREGUY, 1959, p. 285-286). Interessante ressaltar que a duração desses cursos era de três a quatro meses, em regime de internato.

No âmbito da Secretaria de Agricultura (SEAV), criaram-se cinco escolas federais que ofereciam o Curso de Magistério de Economia Rural Doméstica que formava professoras rurais: 1) Escola de Economia Rural Doméstica, Km 47, Antiga Rodovia Rio-São Paulo, Itaguaí, Rio de Janeiro; 2) Escola de Economia Rural Doméstica "Licurgo Leite", em UberabaMG; 3) Escola de Economia Rural Doméstica em Sousa, na Paraíba; 4) Escola de Economia Rural Doméstica da Escola Agrotécnica "Visconde da Gra", Pelotas-RS; 5) Curso de Magistério de Economia Rural Doméstica, da Universidade Rural de Pernambuco. Com apoio da CNER, a SEAV desenvolveu tais projetos de formação com a intenção de "recuperar" a população rural brasileira, objetivando, com isso, a melhoria tanto da produção quanto das condições de vida das comunidades. (FERREIRA, 2014, p. 72).

As Escolas de Magistério de Economia Rural Doméstica, nível de $2^{\circ}$ ciclo, ofereciam currículo de dois anos com a intenção de fornecer à mulher do campo determinados conhecimentos, com a intenção de modificar comportamentos rotineiros por meio da educação. O programa desses cursos contaria com uma configuração teórica e prática, na qual seria possível aprender a fazer com uma "função do ideal de elevar as condições sociais e econômicas da família rural”. (SILVA, 1961, p. 26).

Como elemento modernizador, a priori, pensamos que essa modalidade educacional, escolas normais rurais ou regionais, foi incorporada pelo desenvolvimentismo que imperava nos anos de 1950 a 1963, como um mecanismo de importância para as políticas agrícolas brasileiras, dentre elas, certa política de reforma agrária necessária para a modernização do capitalismo brasileiro, que desconsiderou tanto o contexto rurícola do período como a vontade de seus habitantes. Essa nossa primeira concepção vai ao encontro das análises de Leite, para quem "a modernização do campo nada mais foi do que uma internacionalização da economia brasileira aos interesses monopolistas e a CNER ao realizar seu trabalho educativo desconsiderou as contradições naturais dos grupos campesinos." (LEITE, 1999, p. 37).

Esse mesmo autor ressaltou que a CNER, não observou a oferta de cursos específicos que necessitavam os habitantes do meio rural; além disso, as lutas ou reivindicações das minorias rurais ficaram obscurecidas, sucumbindo diante das expressões comunitárias repassadas pela educação/informação veiculadas na campanha, uma vez que "os pequenos grupos rurais sem representatividade, trabalhadores, sem terra, arrendatários, boias-frias e outros, não tinham vez e nem voz frente às decisões comunitárias." (LEITE, 1999, p. 37).

Ainda assim, João Roberto Moreira (1957) afirmou que o período em estudo trouxe realizações significativas para a educação no Brasil. Moreira creditou os avanços no ensino rural a Anísio Teixeira, cuja presença no Instituto Nacional de Estudos Pedagógicos estimulou inúmeras ações para o ensino rural, que nos anos anteriores se encontrava abandonado, incluindo a construção e a instalação de escolas e formação dos professores. Segundo Lourenço Filho (2001, p. 11), Anísio Teixeira defendia que a formação de um "novo homem, independente e responsável, é o que a escola progressiva deve preparar."

A partir de 1961, com a promulgação da Lei n. ${ }^{\circ}$ 4.024, de 20 de dezembro de 1961, o curso normal teve uma nova configuração. A Lei n. ${ }^{\circ} 4.024$ estabeleceu no Capítulo IV, Da Formação do Magistério para o Ensino Primário e Médio, no Artigo 53:

A formação de docentes para o ensino primário far-se-á:

a) em escola normal de grau ginasial no mínimo de quatro séries anuais onde além das disciplinas obrigatórias do curso secundário ginasial será ministrada preparação pedagógica;

b) em escola normal de grau colegial, de três séries anuais, no mínimo, em prosseguimento grau ginasial. [...] 
Art. 57. A formação de professores, orientadores e supervisores para as escolas rurais primárias poderá ser feita em estabelecimentos que lhes prescrevem a integração no meio. (BRASIL, 1961, p. 8).

Com isso, a partir de 1961, as escolas normais ganham uma nova configuração. Permanecem ainda em funcionamento algumas escolas normais rurais de cunho confessional ou particulares, bem como as que estavam em funcionamento nas instituições federais até 1963, quando as últimas turmas se formam.

\section{Considerações finais}

No período pesquisado as escolas normais rurais ou regionais parecem-nos terem sido marcadas pela intencionalidade dos governos de criar uma concepção/expressão de vida e de cultura da comunidade a que essas escolas pertenceriam e, ao mesmo tempo, iniciar a profissionalização de suas/seus estudantes com vistas ao desenvolvimento regional para «cuidar» do caráter de higienização e civilização das populações rurais. Para tanto, essas escolas deveriam, acima de tudo, promover a especialização, inserir e fixar a professora/o professor e, por conseguinte, a população no meio no qual concretizava seu trabalho educativo.

Os percursos formativos propostos para os cursos normais rurais brasileiros significavam aquilo que as autoridades educacionais do país no período estabeleciam como prioridade para organizar o ensino rural: um ensino que fosse capaz de criar as bases sociais para uma anunciada modernização do campo e das regiões mais afastadas do país. Com isso, a via de modernização concebida para as localidades rurais não se encontrava nas capitais ou nas cidades, mas deveria ser buscada e construída no próprio meio rural. Esse ideário foi sistematizado de forma mais organizada na VIII Conferência Nacional de Educação ou VIII Congresso Nacional de Educação, realizado em 1942, na esteira das ideias difundidas por Sud Mennucci, por Manoel Bergstrom Lourenço Filho e daquele que ficou conhecido como reformador da educação do Ceará, Joaquim Moreira de Sousa, responsável pela fundação da primeira Escola Normal Rural do país e defensor da difusão de escolas normais rurais como modelo de formação de professoras/professores normalistas rurais vinculadas/vinculados às necessidades reais da sociedade.

Naquele Congresso, a relatoria de Sud Mennucci esclareceu que os conferencistas defendiam uma escola para preparo de mestres rurais destinados à atuação nas escolas primárias, as quais deveriam ser fundadas no meio rural considerando os princípios da produção e da cooperação entre os habitantes como a melhor maneira de organização de uma instituição escolar. Era preciso ainda que as instituições escolares e os cursos de formação acontecessem em consonância às necessidades de cada região. Seriam admitidos dois modelos de instituições escolares. a) escolas normais rurais, com duração para a conclusão do curso de formação de professoras para o magistério rural de pelo menos 03 anos; b) escolas regionais, cujo currículo seria mais flexível do que as Escolas Normais Rurais, podendo ter duração varável, de acordo com as regiões nas quais estivessem localizadas, como modo a assegurar melhor orientação e de fixar o professor ao meio, o que traria maior eficiência e alcance para a atuação de professores e professoras, uma vez formados.

A Lei Orgânica do Ensino Normal admitiu, portanto, ao lado das Escolas Normais Rurais, a existência das Escolas Normais Regionais, muitas delas capitaneadas pela CNER, a partir de 1952, para atender às peculiaridades de estados e regiões. Contudo, nas escolas normais rurais, o currículo era diversificado e extenso, enquanto nas escolas regionais os conteúdos eram menos aprofundados e ofertados de forma aligeirada, no tempo mínimo possível. Essas diferenças sugerem a importância dada pelos governantes ao ensino que ofertado nas localidades mais desenvolvidas, em contraposição ao ensino ofertado nas regiões 
mais longínquas, nas pequenas cidades, vilas e zona rural, onde as escolas inexistiam ou naquelas que se encontravam mais distantes dos centros urbanos mais desenvolvidos.

A oposição entre escola normal rural e cursos normais regionais, contudo, não nos parece que possa ser compreendida tão somente como um projeto político para compelir a permanência de homens e mulheres no campo. Essas diferenças, antes parecem sugerir a importância que os governantes brasileiros creditavam ao ensino urbano, em detrimento ao ensino ofertado nas pequenas cidades, vilas e localidades rurais. Cabe ainda observar que o conteúdo ministrado era o mesmo, abordado nas escolas normais rurais de forma mais aprofundada, enquanto nas escolas regionais, o conteúdo a ser abordado seria o mínimo necessário, se comparado ao das escolas normais urbanas, sugerindo o aligeiramento dos conteúdos adotados nas escolas normais rurais ou regionais.

Avaliamos que a trajetória da formação de professores rurais se fez, assim, marcada pela indefinição política dos diversos governos brasileiros e das respectivas reformas promovidas ao longo dos anos. A formação para a educação rural em inúmeras localidades, vilas e pequenas povoações distantes das cidades permanecia desigual em relação às escolas urbanas, fosse em relação à escola primária, fosse em relação às escolas voltadas para a formação de professores.

\section{Referências}

BARROS, Pedro Ferreira. Formação de Professor (as) ruralistas em Juazeiro do Norte (CE) (1934 - 1973): um projeto emancipatório. Tese (Doutorado em Educação) - Universidade Federal do Ceará, Fortaleza, 2011.

BRANDÃO, Carlos Rodrigues. Os professores leigos. Em Aberto, ano 5, n. 32, p. 12 - 15, 1986.

CALAZANS, Maria Julieta Costa; SILVA, Helio R. S.; CASTRO, Luiz Felipe Meira de. Dois programas de educação no meio rural na década de 50: CNER e SSR. Forum Educacional, v.9, n.4, p.43-64, 1985. Disponível em: http://bibliotecadigital.fgv.br/ojs/index.php/fe/article/view/60831. Acesso em: 12 mar. 2018.

FERREIRA, Nilce Vieira Campos. Economia doméstica: ensino profissionalizante feminino no triângulo mineiro (Uberaba/MG - 1953-1997). Jundiaí: Pacto Editorial, 2014.

LEITE, Sérgio Celani. Escola rural: urbanização e políticas educacionais. São Paulo: Cortez, 1999.

LIMA, Sandra Cristina Fagundes de. Historia das escolas rurais em Uberlândia (1933 a 1959). In: PÉREZ, Teresa G.; PÉREZ, Oresta L. (Org.). Educación rural en Iberoamerica. Experiencia histórica y construcción de sentido. Madrid: Ansoart, 2009. p. 153 - 182.

PINHO, Larissa Assis. Civilizar o campo: educação e saúde nos cursos de aperfeiçoamento para professores rurais - Fazenda do Rosário (Minas Gerais, 1947-1956). Dissertação (Mestrado em Educação) - Universidade Federal de Minas Gerais, Belo Horizonte, 2009.

\section{Fontes}

ARREGUY, Colombo Etienne. Rápida visão de conjunto, do panorama brasileiro em que a CNER atua, seus processos de trabalhos, experiências e resultados, orçamento e fundo especial, pessoal, etc. Revista da Campanha Nacional de Educação Rural, ano 6, n. 8, p. 277- 317, 1959. 
BRASIL. Lei n ${ }^{\circ}$ 4.024, de 20 de dezembro de 1961. Fixa as Diretrizes e Bases da Educação Nacional. Disponível em: http://www.planalto.gov.br/ccivil_03/leis/L4024.htm. Acesso em: 19 nov. 2014.

BRASIL. Portaria n. 567 de 10 de agosto de 1953. Institui o Regulamento da Campanha Nacional de Educação Rural. Diário Oficial. Rio de Janeiro, 11 ago. 1953.

HALL, Robert King. Educação rural: tópicos para estudo e análise. Revista Brasileira de Estudos Pedagógicos, v. XIV, n. 39, p. 17 - 40, 1950. Disponível em: http://portal.inep.gov.br/documents/186968/489316/Revista+Brasileira+de+Estudos+Pedag\% C3\%B3gicos+\%28RBEP\%29+-+Num+39/1c40705f-2737-4d5e-8aeade2b69e01bea?version=1.3. Acesso em: 22 jul. 2019.

IBGE. Censo Demográfico 1950/2010. Séries Históricas e Estatísticas. Disponível em: http://seriesestatisticas.ibge.gov.br/series.aspx?vcodigo=CD91\&t=Popula\%u00e7\%u00e3o+p resente $\% 2 c+$ recenseada $\% 2 c+$ residente $\% 2 c+$ por + situa $\%$ u00e $7 \%$ u00e3o+de+domic $\%$ u00edlio +\%28+rural\%2furbana\%29. Acesso em: 27 abr. 2011.

LEITE, Gervásio. Aspecto mato-grossense do ensino rural. In: OITAVO CONGRESSO BRASILEIRO DE EDUCAÇÃO, 1942, Goiânia. Anais. Rio de Janeiro: Serviço Gráfico da Associação Brasileira de Educação, 1944. p. 135 - 142. Disponível em: https://biblioteca.ibge.gov.br/biblioteca-catalogo?id=283807\&view=detalhes. Acesso em: 14 nov. 2017.

LOURENÇO FILHO, Francisco Gago. A valorização do professor rural através dos Centros Regionais de Treinamento de professores rurais. Revista da Campanha Nacional de Educação Rural, v. 3, n. 3, p. 97-103, 1956

LOURENÇO FILHO, Manoel Bergström. A formação de professores - da Escola Normal à Escola de Educação. Brasília. Brasília: Inep/MEC, 2001. Disponível em: http://portal.inep.gov.br/documents/186968/484703/A+forma\%C3\%A7\%C3\%A3o+de+profe ssores+da+Escola+Normal+\%C3\%A0+Escola+de+Educa\%C3\%A7\%C3\%A3o/d98177cf3a25-48f8-982d-246406ca2201?version=1.2. Acesso: 20 jul. 2019.

LOURENÇO FILHO, Manoel Bergström. Preparação de pessoal docente para escolas primárias rurais. Revista Brasileira de Estudos Pedagógicos, v. XX, n. 52, p.61-104, 1953.

LOURENÇO FILHO, Manoel Bergström, Tendências da educação brasileira. Brasília: INEP/MEC, 2002.

MENNUCCI, Sud. A crise brasileira de educação. São Paulo: Editora Piratininga, 1934.

MENNUCCI, Sud. O professor primário das zonas rurais: formação, aperfeiçoamento, remuneração e assistência. In: OITAVO CONGRESSO BRASILEIRO DE EDUCAÇÃO, Goiânia, 1942. Anais. Rio de Janeiro: Serviço Gráfico da Associação Brasileira de Educação, 1944. p.289-300. Disponível em: https://biblioteca.ibge.gov.br/biblioteca-catalogo?id=283807\&view =detalhes. Acesso em: 14 nov. 2017.

MOREIRA, João Roberto. Educação Rural e Educação de Base. Revista Brasileira de Estudos Pedagógicos, v. XXVIII, n. 67, p. 87-129, 1957. 
RBEP. Documentação: IX Congresso Brasileiro de Educação, Revista Brasileira de Estudos Pedagógicos, v. 5, n. 14, p. 259-278, 1945.

ROMERO, Nelson. Campanha Nacional de Educação Rural. In: NÓBREGA, Wandick Londres da (Org.). Enciclopédia da Legislação de Ensino. Rio de Janeiro: Departamento Nacional de Educação do Ministério de Educação e Saúde, 1954, p. 184-193.

SOUSA, Joaquim Moreira de. O professor primário das zonas rurais. Formação, aperfeiçoamento, remuneração e assistência. In: OITAVO CONGRESSO BRASILEIRO DE EDUCAÇÃO, Goiânia, 1942. Anais. Rio de Janeiro: Serviço Gráfico do IBGE, 1944, p. 301 - 306. Disponível em: https://biblioteca.ibge.gov.br/biblioteca-catalogo?id=283807\&view $=$ detalhes. Acesso em: 14 nov. 2017.

SILVA, Noemi Correia. Economia Rural Doméstica: uma realidade na SEAV. In: ENCONTRO DE ECONOMIA DOMÉSTICA, Rio de Janeiro, 1960. Rio de Janeiro: Ministério da Agricultura, 1961. p. 25-32.

SOUZA, Luiz Rogério de. A missão rural e a escola primária. Revista da Campanha Nacional de Educação Rural, ano 3, n. 4, p. 88 - 92, 1956.

UNESCO. International Conference on Education. Recommendations (1934 -1977). Paris, United Nations Educational, Scientific and Cultural Organization, 1979.

VARGAS, Getúlio. Mensagem de Getúlio Vargas ao Congresso Nacional. Apresentada pelo Presidente da República por ocasião da abertura da sessão legislativa de 1951. 15 de março de 1951. p. 102-103. Disponível em: http://brazil.crl.edu/bsd/bsd/u1330. Acesso em: 05 jun. 2016. 